\title{
Modelling of a PMSG Wind Turbine with Autonomous Control
}

\author{
Chia-Nan Wang, Wen-Chang Lin, and Xuan-Khoa Le \\ Industrial Engineering and Management Department, National Kaohsiung University of Applied Sciences, \\ 415 Chien Kung Road, Sanmin District, Kaohsiung 80778, Taiwan \\ Correspondence should be addressed to Chia-Nan Wang; cn.wang@newfancy.com
}

Received 26 February 2014; Accepted 7 April 2014; Published 27 May 2014

Academic Editor: Her-Terng Yau

Copyright (C) 2014 Chia-Nan Wang et al. This is an open access article distributed under the Creative Commons Attribution License, which permits unrestricted use, distribution, and reproduction in any medium, provided the original work is properly cited.

The aim of this research is to model an autonomous control wind turbine driven permanent magnetic synchronous generator (PMSG) which feeds alternating current (AC) power to the utility grid. Furthermore, this research also demonstrates the effects and the efficiency of PMSG wind turbine which is integrated by autonomous controllers. In order for well autonomous control, two voltage source inverters are used to control wind turbine connecting with the grid. The generator-side inverter is used to adjust the synchronous generator as well as separating the generator from the grid when necessary. The grid-side inverter controls the power flow between the direct current (DC) bus and the AC side. Both of them are oriented control by space vector pulse width modulation (PWM) with back-to-back frequency inverter. Moreover, the proportional-integral (PI) controller is enhanced to control both of the inverters and the pitch angle of the wind turbine. Maximum power point tracking (MPPT) is integrated in generator-side inverter to track the maximum power, when wind speed changes. The simulation results in Matlab Simulink 2012b showing the model have good dynamic and static performance. The maximum power can be tracked and the generator wind turbine can be operated with high efficiency.

\section{Introduction}

Renewable energy such as wind power is an important solution to reducing carbon emissions. Nowadays, with the rapid development of wind power technology, wind power can be converted into a useful form of energy, such as using wind turbines-the device that converts kinetic energy from the wind-to make electrical power. In fact, since wind power, as an alternative to fossil fuels, produces no greenhouse gas emissions during operation, it makes a huge difference to our environmental impact. Despite very significant advancements and influence to the environment, wind power costs continue to be greater than the existing low-carbon alternative such as natural gas. Therefore, much research remains to be done in order to improve wind turbines' behaviour and to make them cost-efficient to compete with the traditional energy such as natural gas.

There are many kinds of variable speed generators used for wind turbine. According to the reference $[1,2]$, although doubly fed induction generator (DFIG) is more broadly used than permanent magnetic synchronous generator (PMSG) today, PMSG has some advantages which are counted as experts. Particularly, PMSG is direct drive, has slow rotation speed, does not have rotor current, and can be used without gearbox. The high efficiency and low maintenance will reduce the cost that is the most concern to invest. However, PMSG still has some drawbacks. It needs electromagnetic field with the flexible structure, which leads to the high standard of the production as well as of the operation. Furthermore, variable speed of the generator has to be known by power inverter too.

According to the continuous development of wind power technology, the efficiency of inverter device, facing some tough issues, plays an important role in the improvement of wind power generation system performance. They need to be enhanced by novel controller [3] to improve the efficiency and the reliability. Inside them, MPPT integrating with the back to back space vector PWM [4] is the advantage control novel in [5-8], which is used to measure the rotor speed and compare with the calculated optimal rotor speed. On the other hand, not only does the inverter take an advantage in efficiency control but also the pitch angle controller takes another important part of wind turbine. It is integrated to adjust the aerodynamic torque of the wind turbine when this study rates wind speed. 


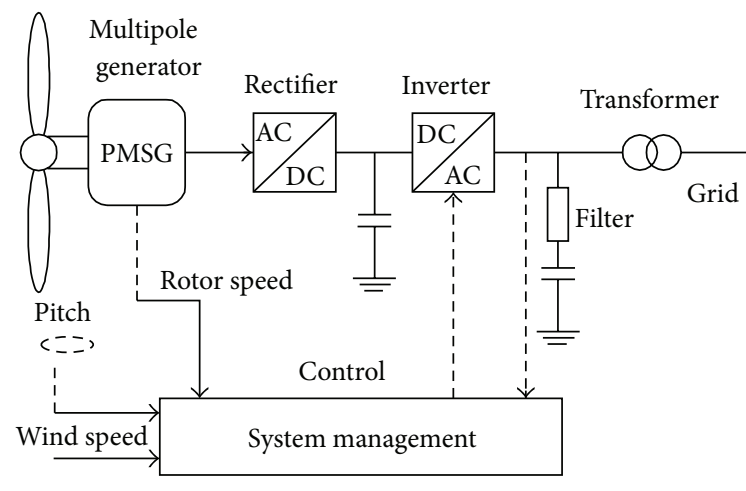

(a)

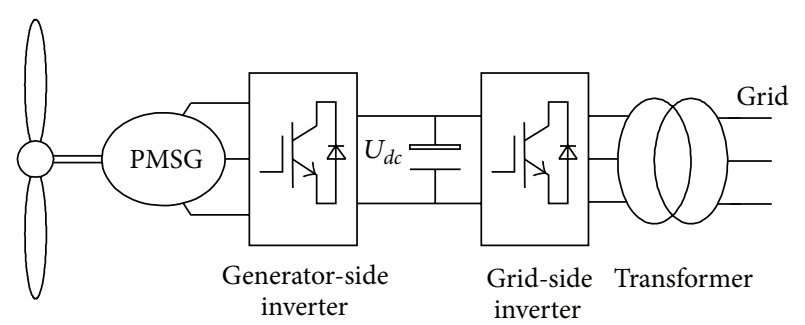

(b)

FIGURE 1: General wind turbine PMSG system with control schemes (a) and (b).

This study will model the whole wind turbine system including physical part of permanent magnet synchronous generator and control strategies for generator side and grid side as well as the pitch angle controller to depict the effects and the efficiency of PMSG by autonomous controllers. The model system and control strategies contain a PMSG wind turbine model, a pitch angle control model, generator-side inverter control model, and grid-side inverter control model. The generator-side inverter and grid-side inverter controller adopt the back to back space vector PWM to enhance the performance of MPPT as well as decoupling control of the active and reactive power by adjusting the current of $d$-axis and $q$-axis of their side inverters. Furthermore, conventional PI controller is also used to improve the control strategy. It is integrated in generator-side inverter, grid-side inverter, and the pitch angle controller. Matlab Simulink 2012b as reference [9] is conducted to simulate and demonstrate the performance. The results will demonstrate the effects and the efficiency of PMSG wind turbine which is integrated by autonomous controllers.

\section{Model of PMSG Wind Turbine}

2.1. Structure of PMSG Wind Turbine. The basic of PMSG wind turbine structure shown on Figure 1 is defined as [10]. The wind turbine generates torque from wind power. The torque is transferred through the generator shaft to the rotor of the generator. The generator produces an electrical torque, and the difference between the mechanical torque from the wind turbine and the electrical torque from the generator determines whether the mechanical system accelerates, decelerates, or remains at constant speed.

The generator is connected to a three-phase inverter which rectifies the current from the generator to charge a DC-link $U_{d c}$ capacitor [11]. The DC-link $U_{d c}$ feeds a second three-phase inverter which is connected to the grid through a transformer. Through the control system, the information of wind speed, pitch angel, rotor RPM, and inverter output is accepted to compare with the grid-side data. Therefore, this information is solved by using a digital signal processing system to produce the correct signal to control these components. The main goal is to synchronize with utility grid and to export power to it.

2.2. Model of Wind Turbine. The wind turbine is used for the conversion of wind kinetic energy to mechanical work. On the basis of relationships for the calculation, it is possible to express the value $P_{m}$ of the aerodynamic wind turbine power $[1,12,13]$ :

$$
P_{m}=0.5 \cdot \rho \cdot A \cdot v^{3} \cdot C_{p}(\lambda, \beta) .
$$

Here, $\rho$ is the air density, $A=\pi \cdot R^{2}$ is the blades swept of the turbine, $v$ is wind speed, and $C_{p}(\lambda, \beta)$ is the power coefficient, which expresses the relationship between the tip speed ratio $\lambda$ and the pitch angle $\beta$.

The power coefficient $C_{p}(\lambda, \beta)$ is as

$$
C_{p}(\lambda, \beta)=0.22\left(\frac{116}{\gamma}-0.4 \cdot \beta-5\right) \cdot \exp \left(-\frac{12.5}{\gamma}\right)
$$

with

$$
\frac{1}{\gamma}=\frac{1}{\lambda+0.089}-\frac{0.035}{\beta^{3}+1}
$$

The relationship between the wind speed and the rotor speed is defined as tip speed ration $\lambda$ :

$$
\lambda=\frac{R \cdot \omega}{v},
$$

where $\omega$ is the blades angular velocity and $R$ is the rotor radius.

From the value of the rotational motion performance, it is possible to determine the value of the torque $T_{m}$ acting on the shaft as follow:

$$
T_{m}=\frac{P_{m}}{\omega} .
$$

These formulas are evident that the instantaneous values of the performance, respectively, of the mechanical torque, 


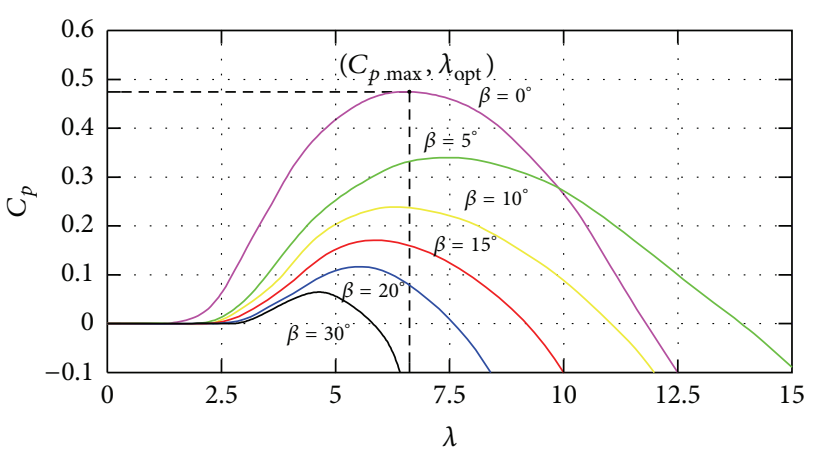

Figure 2: The curve of power wind turbine coefficient.

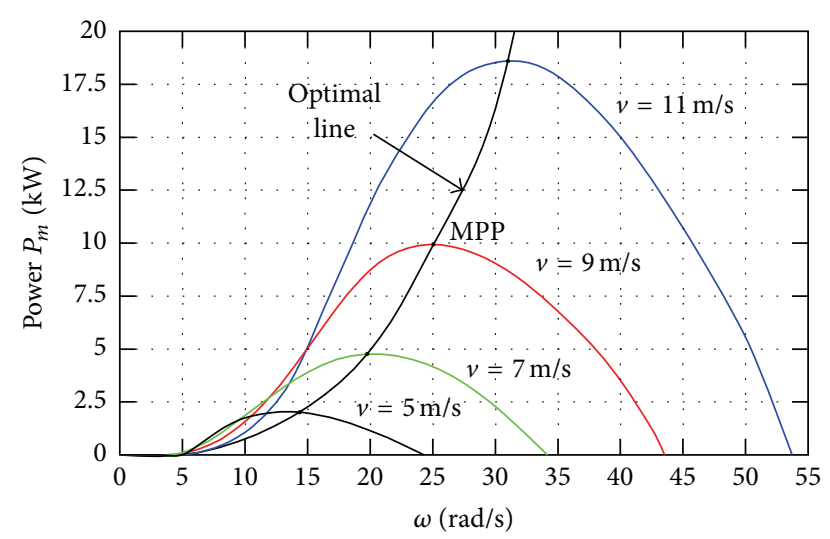

FIGURE 3: The curve to illustrate the relationship between power and wind speed.

are dependent on the wind speed very much. On the basis of these equations, it is possible to build the model, which structure is shown in Figure 4, of the wind turbine in Simulink platform.

Figure 2 shows the curve of power wind turbine coefficient. It reveals that $C_{p}$ achieves the maximum value at the particular $\lambda_{\text {opt }}$.

Figure 3 shows that the rotational speed is a function, in which the power captured in turbine blade obtains the maximum output at the particular rotational speed, while the pitch angle is constant. Hence, $\lambda$ should be kept at $\lambda_{\text {opt }}$ to maximize the wind energy.

In Figure $4, f(u)$ of Lambda, Gama, and $C_{p}$ are defined in the order of equations (4), (3), and (2). If wind speed is in the range from $3 \mathrm{~m} / \mathrm{s}$ to cut out $25 \mathrm{~m} / \mathrm{s}$, it is combined to form turbine torque $f(u)$ as (1) and (5).

2.3. Model of Permanent Magnet Synchronous Generator. The generator model is implemented entirely in $d q$-coordinates. It means that there are no AC-states in the model. The generator is modelled with DC voltages and currents in a rotor-fixed rotating coordinate system which is illustrated in Figure 5.
The equations for the $d$-axis and $q$-axis currents are defined in $[1-3]$ as

$$
\begin{gathered}
\frac{d i_{s d}}{d t}=-\frac{R_{s a}}{L_{s d}} i_{s d}+\omega_{s} \frac{L_{s q}}{L_{s d}} i_{s q}+\frac{1}{L_{s d}} u_{s d} \\
\frac{d i_{s q}}{d t}=-\frac{R_{s a}}{L_{s q}} i_{s q}-\omega_{s}\left(\frac{L_{s d}}{L_{s q}} i_{s d}+\frac{1}{L_{s q}} \psi_{p}\right)+\frac{1}{L_{s q}} u_{s q} .
\end{gathered}
$$

The equation of the electromagnetic torque in the rotor is

$$
T_{e}=1.5 \frac{P}{2}\left[\psi_{p} i_{s q}+i_{s d} i_{s q}\left(L_{s d}-L_{s q}\right)\right] .
$$

There, $i_{s d}, i_{s q}, u_{s d}$, and $u_{s q}$ are the $d$-axis and $q$-axis currents and voltages respective stator resistance; $\omega_{s}$ is the basic electrical angular frequency of the generator; $L_{s d}$ and $L_{s q}$ are the inductance of generator; $\psi_{p}$ is permanent flux; $R_{s a}$ is the resistance of stator; and $P$ is the number of poles.

Figure 5 shows the $d q$-coordinates frame of the PMSG with $\theta$ being the angle between $d$-axis and the main stator axis.

\section{Autonomous Control of PMSG Wind Turbine}

3.1. Generator-Side Inverter Controller. The generator-side inverter is controlled to catch maximum power from available wind power. According to (7), in order to control the electromagnetic torque $T_{e}$, this study just controls the $q$-axis current $i_{s q}$ with the assumption that the $d$-axis current $i_{s d}$ is equal to zero. Furthermore, $[3,14]$ show that, in order to catch maximum power, the optimum value of the rotation speed is adjusted. The tip speed ratio $\lambda$ is taken into account due to the equation being addressed as follow:

$$
\omega_{\text {ref }}=\frac{\lambda_{\mathrm{opt}} \cdot v}{R} .
$$

There, $\omega_{\text {ref }}$ is the blades angular velocity reference and $\lambda_{\text {opt }}$ is the tip speed ratio optimum.

From (6), it is calculated that

$$
\begin{gathered}
U_{s d}=R_{s a} \cdot i_{s d}-\omega_{s} \cdot L_{s q} \cdot i_{s q}+\frac{d i_{s d}}{d t} \cdot L_{s d} \\
U_{s q}=R_{s a} \cdot i_{s q}+\omega_{s} \cdot L_{s d} \cdot i_{s d}+\frac{d i_{s q}}{d t} \cdot L_{s q}+E_{s},
\end{gathered}
$$

with $E_{s}=\omega_{s} \cdot \psi_{p}$ being the permanent flux linkages.

The generator-side inverter control schematic is illustrated in Figure 6. Through the MPPT in [5], the error of $\omega_{\text {ref }}$ is produced. Therefore, the error of $\omega_{\text {ref }}$ and $\omega_{s}$ is rescued to PI controller to produce $q$-axis current component $i_{s q \text { ref }}$ which put into space vector pulse width modulation (SVPWM). The $d_{\text {-axis current }} i_{\text {sd_ref }}$ is set to zero because the $d$-axis current control is adopted. Consequently, through the SVPWM containing voltage feed-forward compensation, the power factors of the generator are calculated and controlled well. 


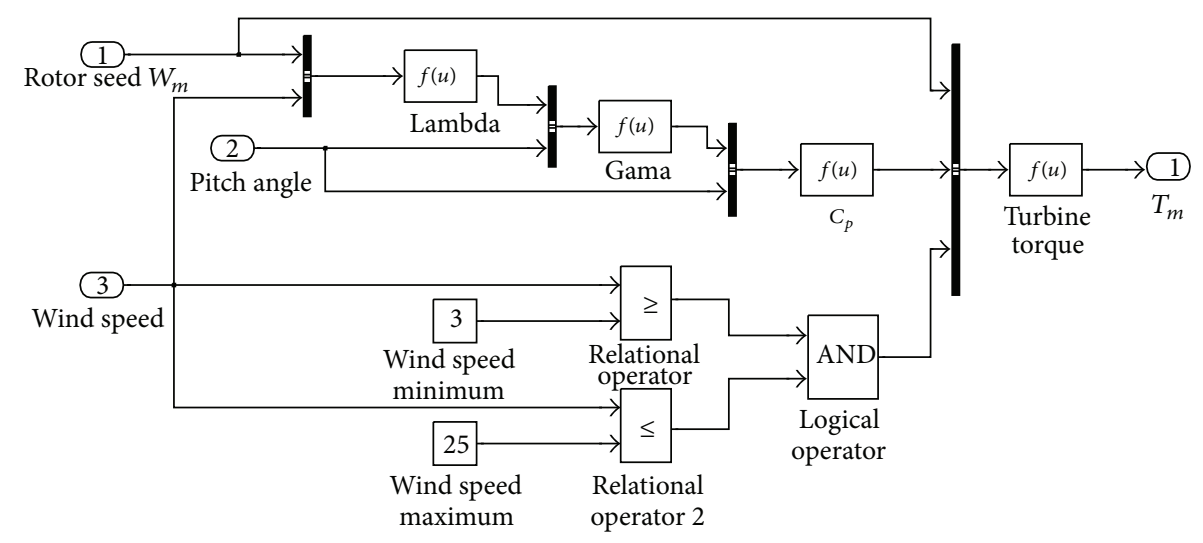

Figure 4: Model of the aerodynamic of wind turbine in Matlab Simulink 2010b.

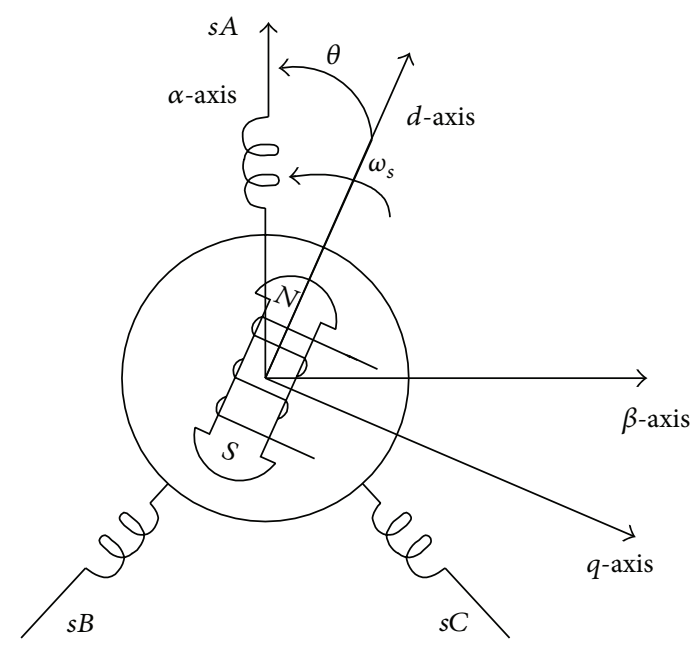

Figure 5: The $d q$-coordinate frame of the PMSG.

3.2. Grid-Side Inverter Controller. The goal of the grid-side inverter is keeping the stability of the DC-line voltage [15$18]$ as well as controlling the active and reactive power $[3,19]$. For the grid/transformer inductance, the model is given as follows:

$$
\begin{gathered}
u_{d}=e_{d}-R \cdot i_{d}+\omega \cdot L \cdot i_{q}-L \cdot \frac{d i_{d}}{d t}, \\
u_{q}=-R \cdot i_{q}-\omega \cdot L \cdot i_{d}-L \cdot \frac{d i_{q}}{d t} .
\end{gathered}
$$

Here, $e_{d}$ is the $d$-axis output voltage of the grid, respectively, $\omega$ is the angular frequency in electrical degree of grid, $R$ is the resistance, $L$ is the inductance, respectively, and $i_{d}$ and $i_{q}$ are the currents of $d$-axis and $q$-axis. By (10), it is easy to figure out that the current of $d$-axis and $q$-axis can be controlled to moderate the active and reactive power. In Figure 7, the loop voltage and the loop current are illustrated. The inner current loop is controlled through PI controller similar to generatorside inverter controller. The output voltage loop produces PI controller for calculating the error between $U_{d c}$ and $U_{d c_{\text {_ref }}}$ to produce $i_{d_{-} \text {ref }}$. Therefore, $q$-axis current is set to be zero to decoupling control of the active power $P$ and reactive power $Q$ by moderating the $d$-axis current $i_{d}$ and the $q$-axis current $i_{q}$.

3.3. Pitch Angle Controller. The system of aerodynamic control plays an important role in regulating the mechanical power. Pitch angle controller is based on the principle which is changing the blades angle at the revolutions over the maximal generator speed as well as protecting the generator before overloading at high wind speeds. The optimal angle for the wind speed below the nominal value is approximately zero and then it increases with the wind speed growing. It has considerable impact on the performance coefficient and on the value of the turbine torque in [20].

In this controller, illustrated in Figure 8, the speed of the generator which is the input is compared with its reference value through PI controller to have the output value of the pitch angle of the blades, which changes the performance coefficient of the turbine.

3.4. Maximum Power Point Tracking (MPPT). In the generator-side inverter, MPPT produces the $\omega_{\text {ref }}$ for the comparative PI controller. According to Figure 3 and [5-8], the wind turbine coefficient achieves the maximum for the tip speed, when the pitch angle $\beta=0$. In terms of every wind speed, there exists a specific point to get the maximum output. Hence, in order to control the maximum power in every wind speed, the MPPT tracks the continuous line and optimal line in Figure 9.

The tip speed ratio is kept at constant value for all maximum power points, while the relationship between the wind speed and the wind turbine generator speed is explained as follows:

$$
\Omega_{n}=\lambda_{n} \frac{V_{n}}{R}
$$

with $\Omega_{n}$ being the optimal rotation wind turbine generator at the wind speed $V_{n}$.

The MPPT control strategy is based on monitoring the wind turbine generator output power using measurements of the wind turbine generator output voltage and current as well 


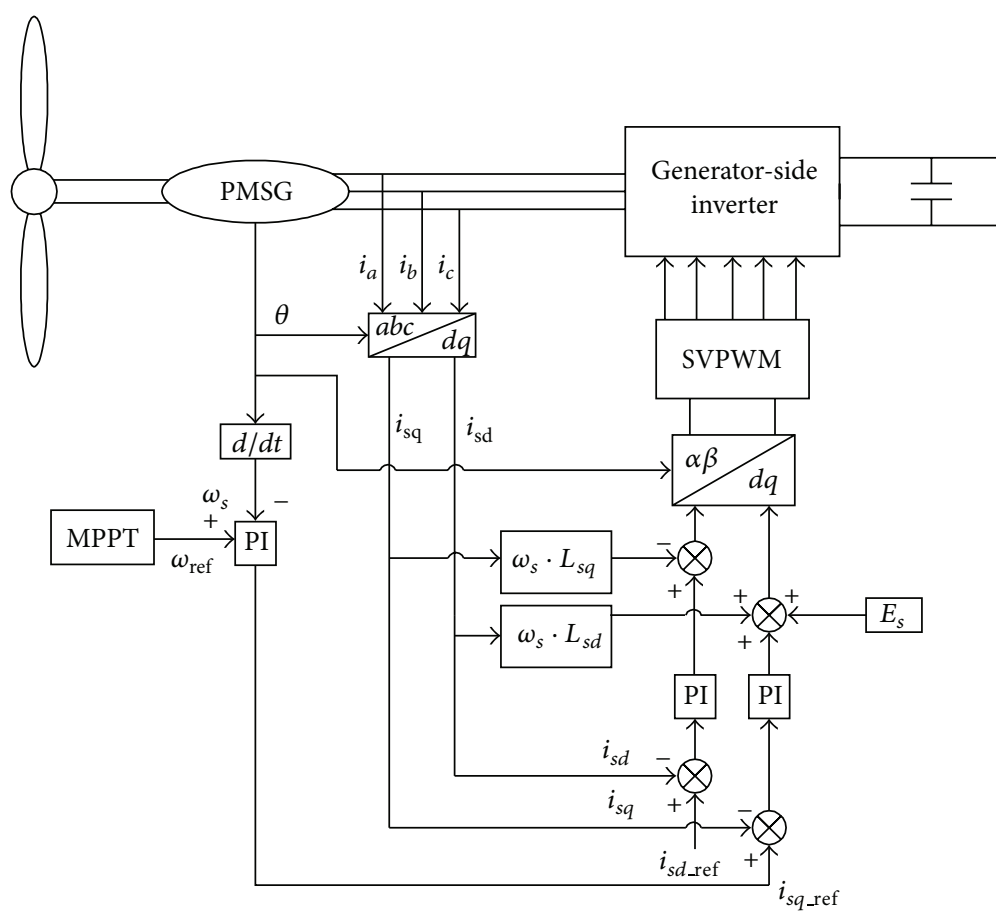

FIGURE 6: Scheme of generator-side inverter controller.

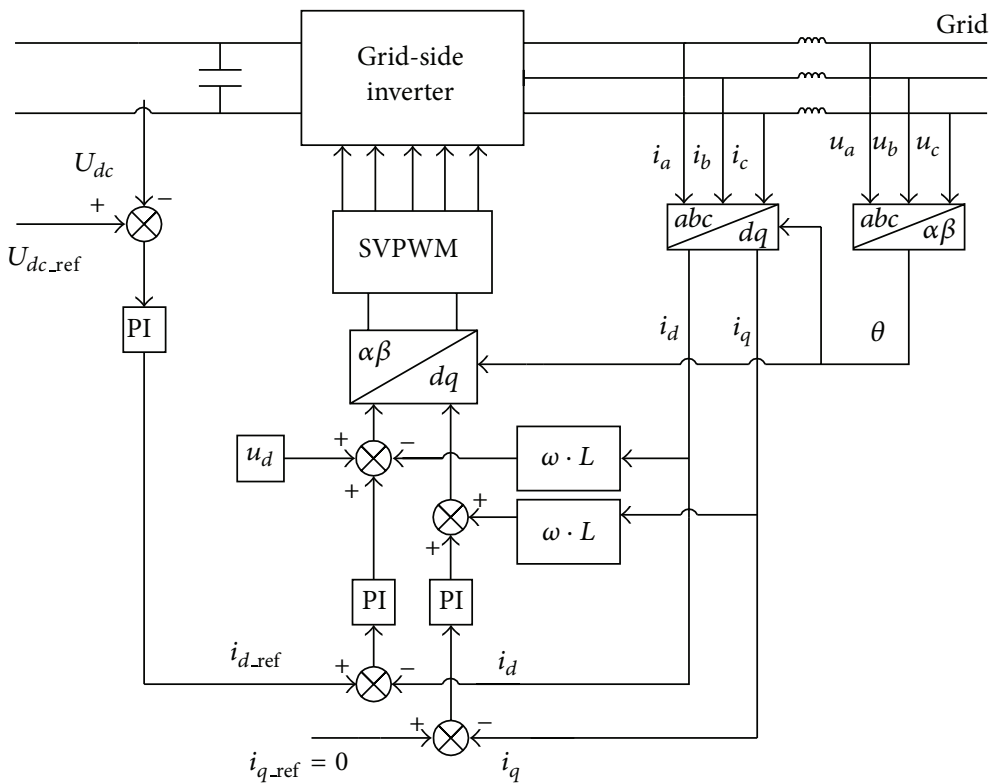

Figure 7: Scheme of grid-side inverter controller.

as directly modelling the dc/dc converter duty cycle, which is followed by the comparison of among output power values.

\section{Simulation Analysis}

In order to verify the model of the whole autonomous control system design, Matlab 2010b is used to simulate this system design in Figure 10.
Model of wind turbine is in wind turbine; models of control system of generator-side inverter and grid-side inverter are included in Subsystem 1 and Subsystem 2. The MPPT controller and PI controller are also included in Subsystem 1 and Subsystem 2. The pitch angle controller is completely modelled in wind turbine. In this simulation, the wind turbine PMSG model obtains the wind speed and provides an optimal reference speed to control the system. The simulation results are shown in Figures 11-14. 


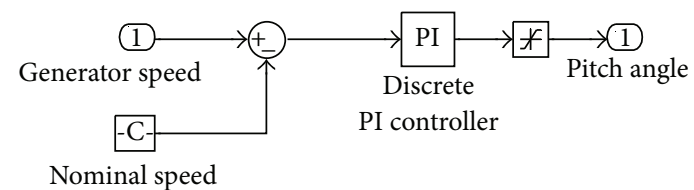

FIGURE 8: Model of pitch angle controller in Matlab Simulink 2010b.

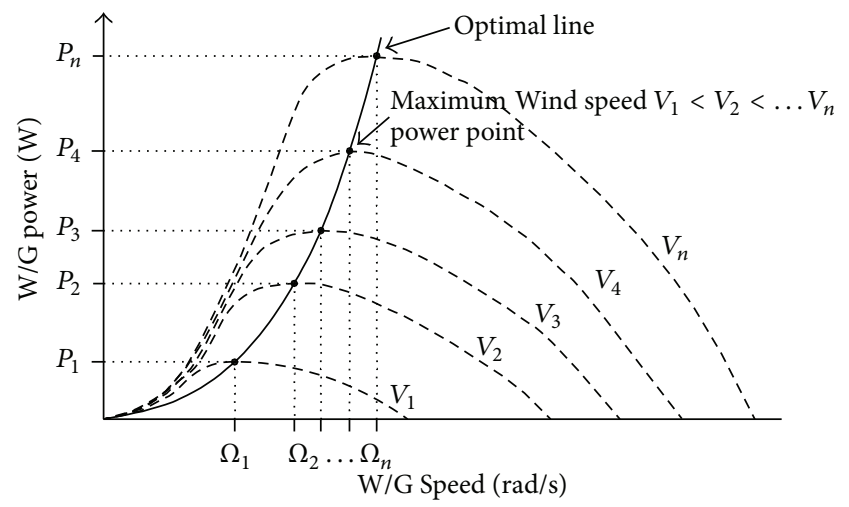

FIGURE 9: Wind turbine generator power curve at various wind speeds.

The main system parameters are listed in Table 1 according to the design consideration. The original states of the system are zero. When wind speed is $12 \mathrm{~m} / \mathrm{s}$, optimal speed of PMSG is obtained. Pitch angle controller catches the optimum tip speed ratio at 8 and optimum power coefficient at 0.4 through the maximum power point tracking. On the other hand, grid-side inverter models the output voltage with the DC-link voltage $1200 \mathrm{~V}$ in accordance with DClink capacitor $15000 \mu \mathrm{F}$. After all, PMSG wind turbine with autonomous control system produces the grid line voltage at $900 \mathrm{~V}$.

Figure 11 shows the waves of DC-link voltage, the voltage is produced by grid-side inverter and A-phase voltage feeding to the grid. Through the results, it is admitted that DCvoltage is well controlled in stabilizing performance with the fluctuation being about $25 \%$. When $V_{a b}$ passes through the inverter, load voltage slightly fluctuates by the late modelling during $0 \mathrm{~s}$ to $0.08 \mathrm{~s}$. After that, the load voltage can be kept in stable output.

Figure 12 shows the wave forms of $d$-current, voltage phase of PMSG, and $d$-voltage reference. According to the results, it can be revealed that, despite the usual change of wind speed, the $d$-axis current is still modelled to be maintained at zero level off.

The voltage phase per unit (pu) of PMSG is decreased after the beginning stage; however, it keeps constant value at that later time.

Figure 13 shows the waves of three-phase voltage and current of the grid when autonomous PMSG wind turbine is operated at stable state. Voltage phase almost opposes the current phase.

Figure 14 performs the waves of active power and reactive power decoupling control. When the wind turbine catches the
TABLE 1: The parameters of autonomous control PMSG wind turbine.

\begin{tabular}{ll}
\hline & Rated voltage of stator: $5 \mathrm{KV}$ \\
& Rated frequency of stator: $50 \mathrm{~Hz}$ \\
& Rated rotor torque: $450 \mathrm{~N} \cdot \mathrm{m}$ \\
& Stator phase resistance: $0.01 \Omega$ \\
& Armature inductance: $0.03 \mathrm{H}$ \\
& $d$-axis inductance: $5.5 \mathrm{mH}$ \\
& q-axis inductance: $3.75 \mathrm{mH}$ \\
& Number of poles: 56 \\
\hline Rated power: $2 \mathrm{MW}$ \\
Blades radius: $35 \mathrm{~m}$ \\
Optimum tip-speed ratio: 8 \\
Optimum power coefficient: 0.4 \\
Air density: $1.225 \mathrm{~kg} / \mathrm{m}^{3}$ \\
Cut-in wind speed: $3 \mathrm{~m} / \mathrm{s}$ \\
Rated wind speed: $12 \mathrm{~m} / \mathrm{s}$ \\
Cut-out wind speed: $25 \mathrm{~m} / \mathrm{s}$ \\
\hline Grid line voltage: $900 \mathrm{~V}$ \\
DC-link voltage: $1200 \mathrm{~V}$ \\
DC-link capacitor: $15000 \mu \mathrm{F}$ \\
Transformer output voltage: $12 \mathrm{KV}$ \\
Frequency: $50 \mathrm{~Hz}$ \\
\hline
\end{tabular}

wind speed at rate $4 \mathrm{~m} / \mathrm{s}, \mathrm{PMSG}$ begins to operate. Therefore, the pitch angle is controlled to catch the maximum coefficient at rate $13 \mathrm{~m} / \mathrm{s}$ wind speed. After $0.14 \mathrm{~s}$, the generator-side inverter and the grid-side inverter are cooperated to control the voltage through controllers. The wind turbine gets the stable output power to the grid with standard voltage, frequency, and phase.

By the autonomous control, including pitch angle controller, generator-side inverter, and grid-side inverter, the wind turbine is able to achieve the highest efficiency. Through the MPPT strategy as well as pitch angle controller, it can catch the maximum wind energy and operate at optimal speed ratio.

\section{Conclusions}

This study analyzes the control strategies as well as models and designs and simulates the whole autonomous system of PMSG wind turbine feeding AC power to the utility grid in Matlab Simulink 2010b. The simulation results show that the combination of pitch angle controller, generator-side inverter controller, and grid-side inverter controller has good dynamic and static performance. The maximum power can be tracked and the generator wind turbine can be operated in high efficiency. DC-link voltage is kept at stable level for decoupling control of active and reactive power. Hence, the output will get the optimum power supply for the grid. 


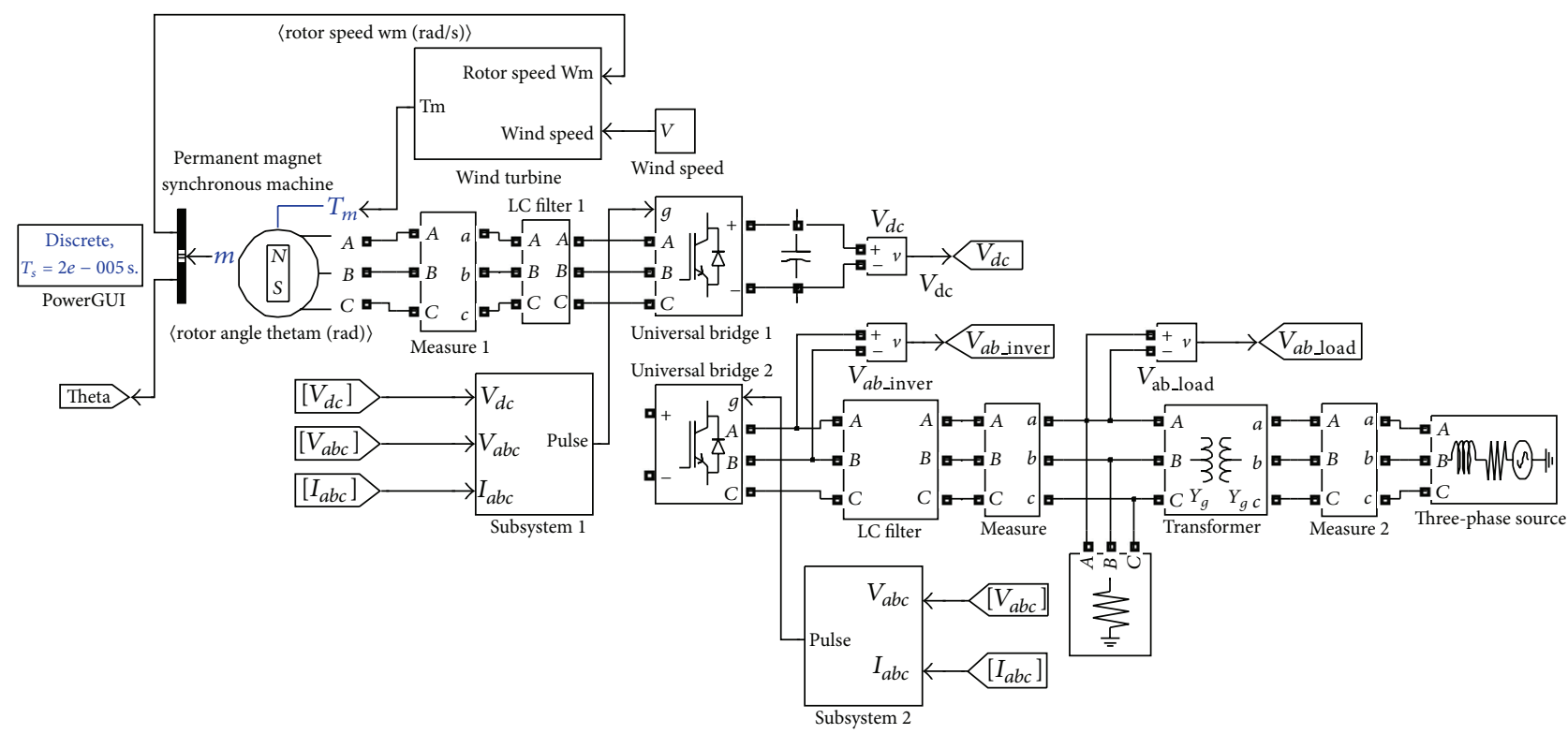

FIGURE 10: Simulation model of autonomous control PMSG wind turbine.

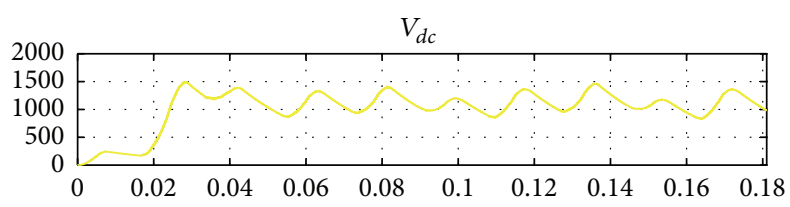

(a)

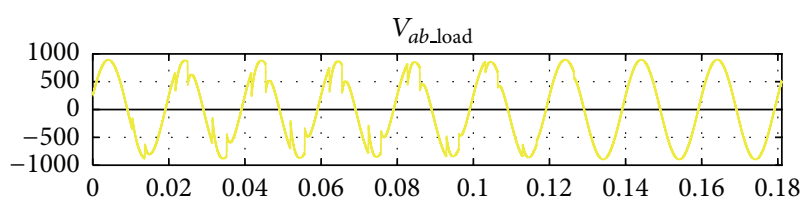

(b)

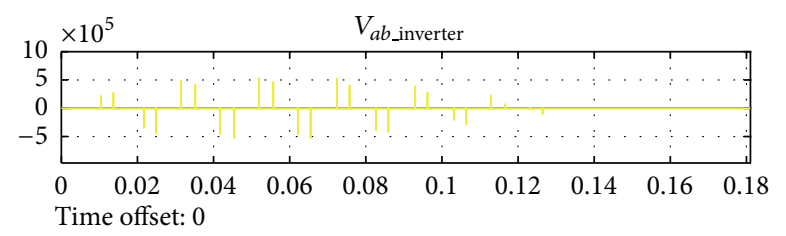

(c)

FIGURE 11: DC-link voltage, load voltage, and inverter voltage.

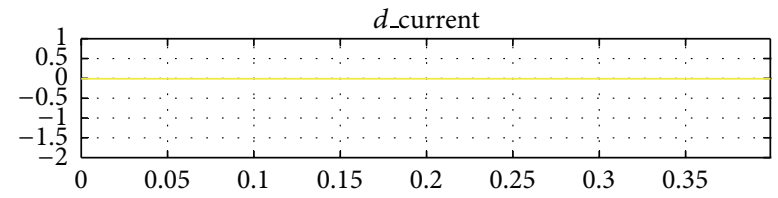

(a)

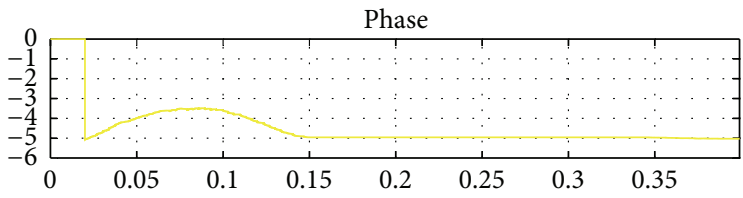

(b)

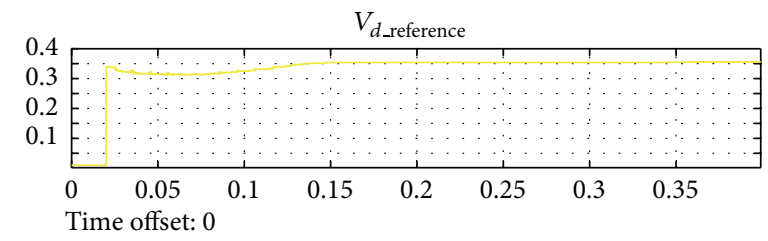

(c)

FIGURE 12: $d$-current, voltage phase of PMSG, and $d$-voltage reference (pu). 


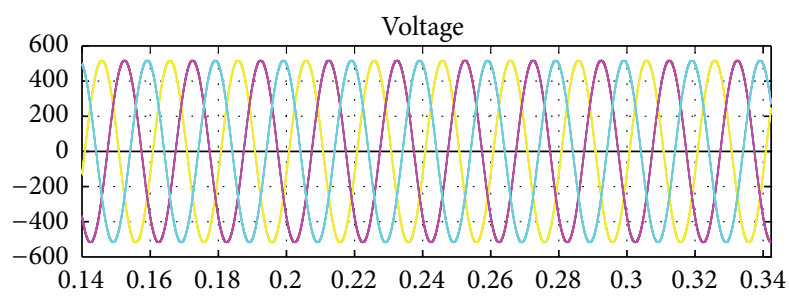

(a)

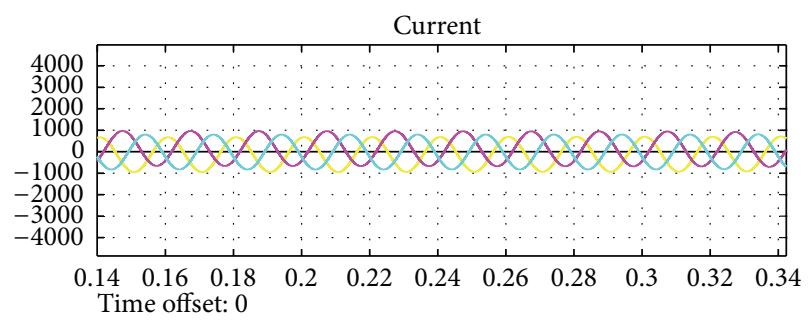

(b)

FIGURE 13: Three-phase voltage and current of the grid.

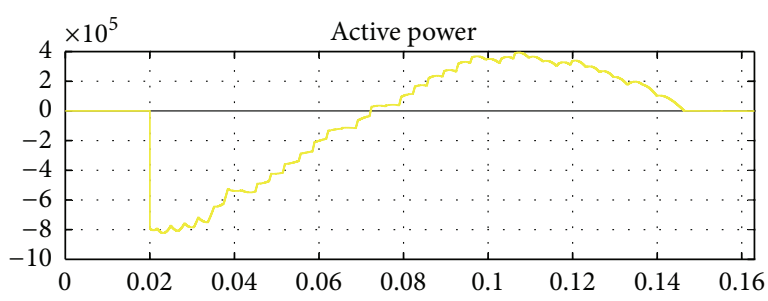

(a)

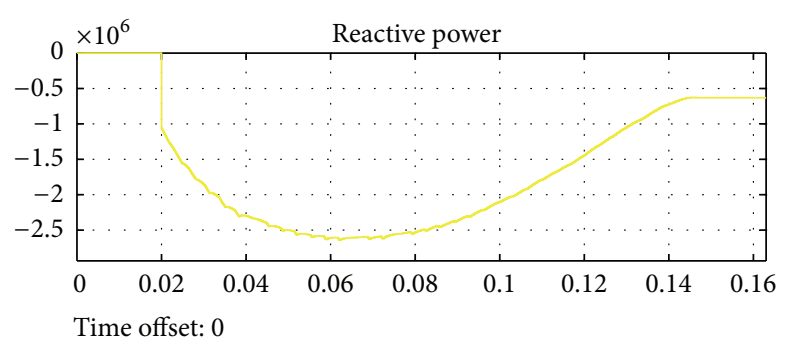

(b)

FIGURE 14: Active and reactive power.

\section{Conflict of Interests}

The authors declare that they have no conflict of interests regarding the publication of this paper.

\section{References}

[1] J. Chen, H. B. Wu, M. Sun, W. N. Jiang, L. Cai, and C. Y. Guo, "Modeling and simulation of directly driven wind turbine with permanent magnet synchronous generator," in Proceedings of the 2012 IEEE Innovative Smart Grid Technologies, Asia (ISGT '12), pp. 1-5, May 2012.

[2] A. Binder and T. Schneider, "Permanent magnet synchronous generators for regenerative energy conversion-a survey," in Proceedings of the 2005 European Conference on Power Electronics and Applications, pp. 11-14, September 2005.

[3] S. Li, T. A. Haskew, and L. Xu, "Conventional and novel control designs for direct driven PMSG wind turbines," Electric Power Systems Research, vol. 80, no. 3, pp. 328-338, 2010.

[4] K. H. Kim, Y. C. Jeung, D. C. Lee, and H. G. Kim, "Robust control of PMSG wind turbine systems with back-to-back PWM converters," in Proceedings of the 2nd International Symposium on Power Electronics for Distributed Generation Systems (PEDG '10), pp. 433-437, June 2010.

[5] E. Koutroulis and K. Kalaitzakis, "Design of a maximum power tracking system for wind-energy-conversion applications," IEEE Transactions on Industrial Electronics, vol. 53, no. 2, pp. 486-494, 2006.

[6] R. Datta and V. T. Ranganathan, "A method of tracking the peak power points for a variable speed wind energy conversion system," IEEE Transactions on Energy Conversion, vol. 18, no. 1, pp. 163-168, 2003.

[7] A. M. De Broe, S. Drouilhet, and V. Gevorgian, "A peak power tracker for small wind turbines in battery charging applications," IEEE Transactions on Energy Conversion, vol. 14, no. 4, pp. 1630-1635, 1999.

[8] Q. Wang and L. Chang, "Independent maximum power extraction strategy for wind energy conversion systems," in Proceedings of the 1999 IEEE Canadian Conference on Electrical and Computer Engineering, vol. 2, pp. 1142-1147, May 1999.

[9] F. Iov, A. Hansen, P. Sorensen, and F. Blaabjerg, Wind Turbine Block Set in Matlab/Simulink, Aalborg University and RISO, 2004.

[10] A. Rolán, Á. Luna, G. Vázquez, D. Aguilar, and G. Azevedo, "Modeling of a variable speed wind turbine with a permanent magnet synchronous generator," in Proceedings of the IEEE International Symposium on Industrial Electronics (ISIE '09), pp. 734-739, July 2009.

[11] X. Yuan, F. Wang, D. Boroyevich, R. Burgos, and Y. Li, "DClink voltage control of a full power converter for wind generator operating in weak-grid systems," IEEE Transactions on Power Electronics, vol. 24, no. 9, pp. 2178-2192, 2009.

[12] M. Yin, G. Li, M. Zhou, and C. Y. Zhao, "Modeling of the wind turbine with a permanent magnet synchronous generator for integration," in Proceedings of the 2007 IEEE Power Engineering Society General Meeting, pp. 1-6, June 2007.

[13] A. D. Hansen and G. Michalke, "Modelling and control of variable-speed multi-pole permanent magnet synchronous generator wind turbine," Wind Energy, vol. 11, no. 5, pp. 537-554, 2008.

[14] M. Chinchilla, S. Arnaltes, and J. C. Burgos, "Control of permanent-magnet generators applied to variable-speed windenergy systems connected to the grid," IEEE Transactions on Energy Conversion, vol. 21, no. 1, pp. 130-135, 2006.

[15] J. Marques, H. Pinheiro, H. Grübdling, and L. Hey, "A survey on variable-speed wind turbine system," in Proceedings of the Cientifico Greater Forum of Brazillian Electronics of Power, vol. 1, pp. 732-738, September 2003. 
[16] B. S. Borowy and Z. M. Salameh, "Dynamic response of a stand-alone wind energy conversion system with battery energy storage to a wind gust," IEEE Transactions on Energy Conversion, vol. 12, no. 1, pp. 73-78, 1997.

[17] V. Valtchev, A. van den Bossche, J. Ghijselen, and J. Melkebeek, "Autonomous renewable energy conversion system," Renewable Energy, vol. 19, no. 1-2, pp. 259-275, 2000.

[18] Y. Chuanwei, L. Hui, and J. Jiuchun, "Modeling and simulation of AC-DC-AC converter system for MW-level direct-drive wind turbine grid interface," in Proceedings of the 37th IEEE Power Electronics Specialists Conference (PESC '06), pp. 1-4, June 2006.

[19] S. Zhang, K. J. Tseng, D. M. Vilathgamuwa, T. D. Nguyen, and X. Y. Wang, "Design of a robust grid interface system for pmsgbased wind turbine generators," IEEE Transactions on Industrial Electronics, vol. 58, no. 1, pp. 316-328, 2011.

[20] E. Muljadi, "Pitch-controlled variable-speed wind turbine generation," IEEE Transactions on Industry Applications, vol. 37, no. 1, pp. 240-246, 2001. 


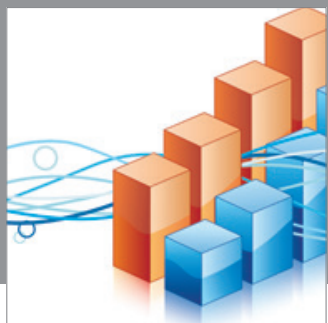

Advances in

Operations Research

mansans

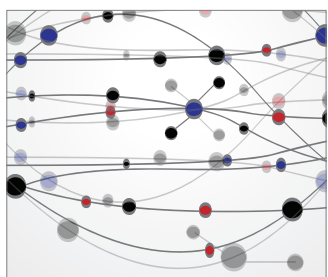

The Scientific World Journal
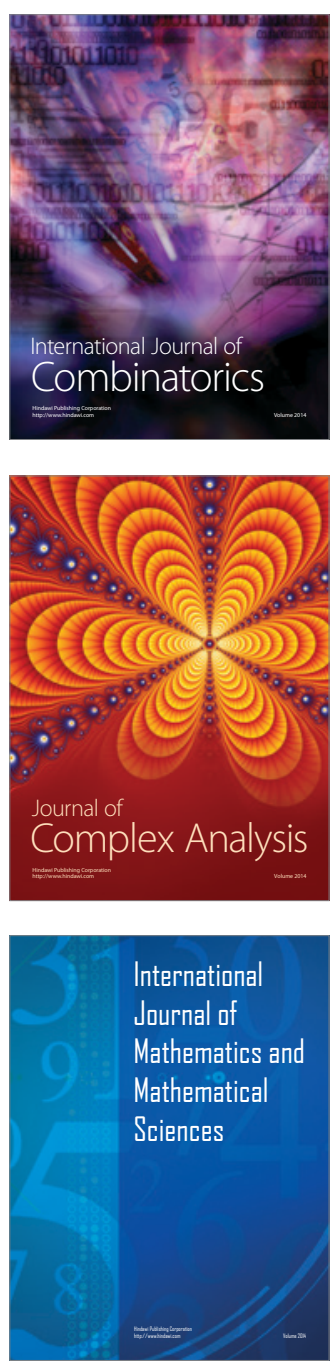
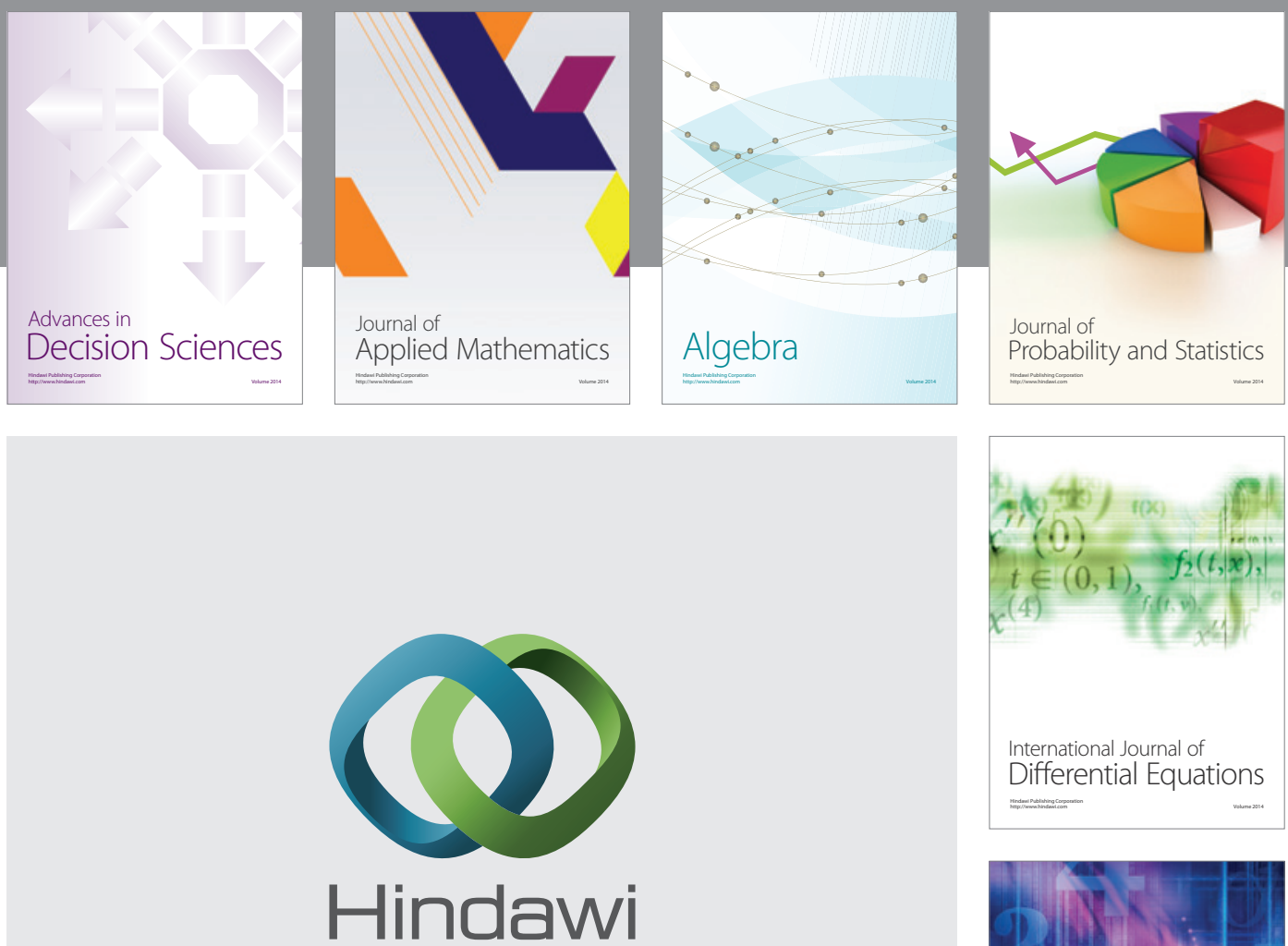

Submit your manuscripts at http://www.hindawi.com
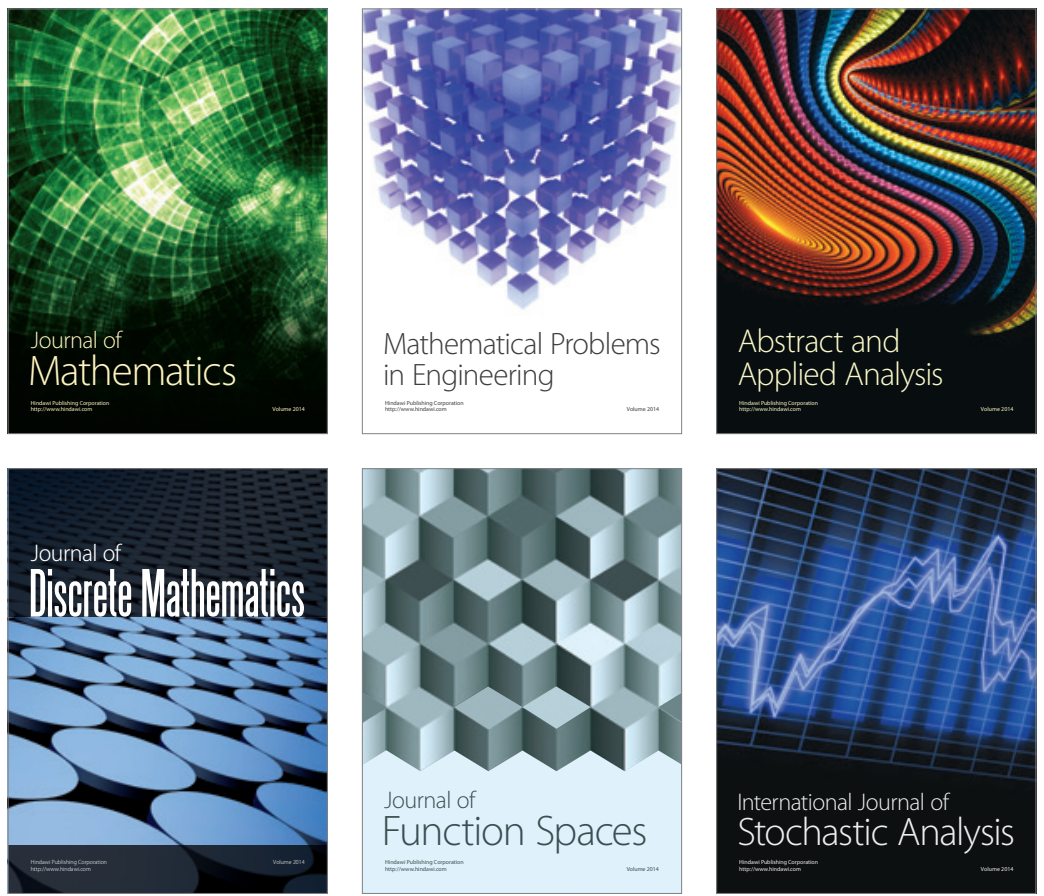

Journal of

Function Spaces

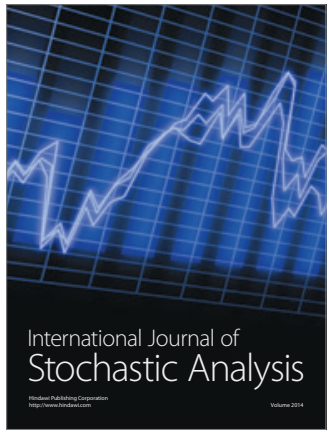

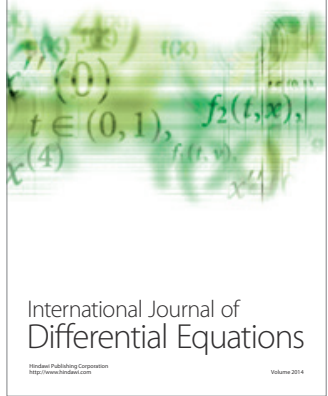
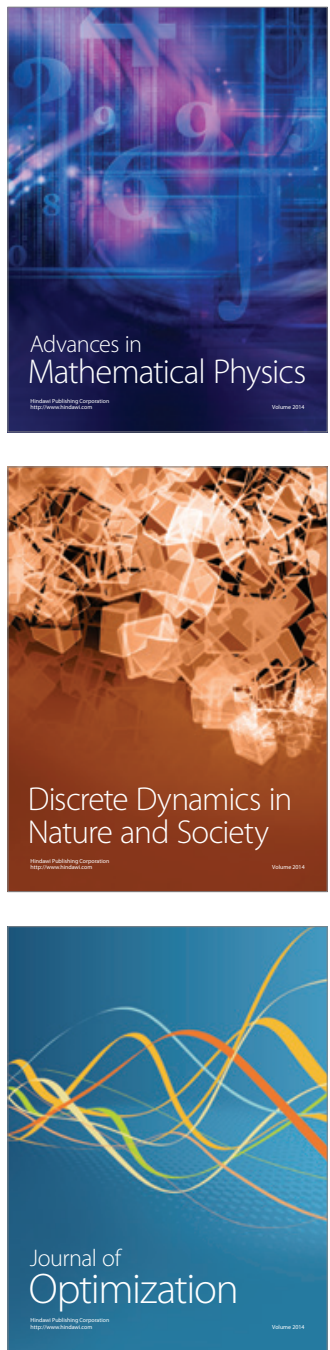